\title{
Media Pembelajaran Digital Sebagai Inovasi Pembelajaran Debat Dalam Forum Diskusi Pada Masa Pandemi Covid-19
}

\author{
Masni Fatimah \\ E-mail: masnifatimah28@gmail.com \\ Program Studi Pendidikan Bahasa dan Sastra Indonesia, Universitas Riau
}

\section{Pengantar}

Sejak pandemi covid-19 yang melanda dunia termasuk Indonesia membuat segala kegiatan tidak bisa dilakukan sepenuhnya dengan lancar. Hal ini mambuat kesulitan yang dialami masyarakat akibat terbatasnya segala urusan dibidang apapun tidak terkecuali pada bidang pendidikan. Sejak ditetapkannya pembelajaran secara daring membuat guru yang terutama harus mencari solusi metode pembelajaran agar tetap terlaksana dengan baik. Tidak hanya itu siswa juga dituntut untuk belajar secara mandiri dan terampil agar tujuan pembelajaran itu dapat tercapai. Menurut (Zulhafizh, Atmazaki, \& Syahrul, 2013) sikap dan motivasi belajar yang tinggi pada siswa diharapkan dapat membantu dalam pencapaian hasil belajar yang maksimal.

Dalam kontek belajar daring di masa covid-19, kualitas belajar tidak diharapkan menurun tetapi terus meningkat. Jika kualitas belajar menurun, maka dapat memberikan dampak mutu capaian belajar wawasan dan pengalamannya (Zulhafizh, Atmazaki, \& Syahrul, 2013). Hal ini menjadi patokan jika bentuk pembelajaran yang dilakukan tidak tercapai dan tidak memberikan perubahan ke arah yang lebih baik maka kualitas dan prestasi belajar peserta didik akan menurun juga. Perlu disadari adanya suatu bentuk inovasi pembelajaran yang dilakukan agar pembelajaran bisa tercapai dengan baik.

Menurut Ikla Zufria (2016) pembelajaran jarak jauh akan efektif jika melibatkan interaksi antara pembelajar dengan pengajar, pembelajar dengan pembelajar, pembelajar dengan media (termasuk fasilitas) pembelajaran. Pola interaksi pembelajaran berlangsung secara aktif dan interaktif. Media pembelajaran atau trade-off teknologi yang digunakan dalam interaksi 'face-to- 
face' langsung antara pembelajar dan pengajar seperti halnya dalam pembelajaran konvensional dapat dicapai atau setidaknya mendekati. Penggunaan teknologi dalam menunjang pembelajaran jarak jauh harus diperhatikan untuk membantu pendidikan.

Di zaman yang semakin modern ini memberikan perubahan-perubahan terutama dibidang teknologi yang semakin canggih. Banyaknya penemuanpenemuan dan ciptaan baru yang bisa dimanfaatkan dan mendukung suatu kegiatan seperti pada bidang pendidikan. Menurut Zulhafizh \& Silvia Permatasari (2020) kondisi ini mengubah tatanan cara belajar peserta didik dan para pendidik.

Peranan media digital tidak pernah tinggal dalam kehidupan mulai dari tempat berkomunikasi hingga penunjang kegiatan. Sebelumnya pemanfaatan media digital pada pendidikan sudah direalisasikan walaupun tidak secara penuh dan hanya beberapa saja yang manfaatkannya. Situasi pandemi covid-19 ini menjadikan peranan media digital semakin meningkat. Terkhususnya pada bidang pendidikan dikarenakan pembelajaran dilakukan secara daring, pemanfaatanpemanfaatan media digital seperti aplikasi sangat dibutuhkan untuk menunjang proses pembelajaran. Menurut Kaiful Usman (2013) media digital dapat menyajikan materi pembelajaran secara kontekstual, audio maupun visual secara menarik dan interaktif. Menurut Putu Wisnu Saputra \& I Gede Dharman Gunawan (2021) terkait dengan urgent-nya media pembelajaran berbasis digitalisasi dewas ini mengharuskan pendidik benar-benar kreatif dan inovatif untuk menciptakan media-media pembelajaran untuk mempermudah pemahaman peserta didik akan materi pelajaran. Pembelajaran debat dalam forum diskusi salah satunya harus mempraktikkan tata cara berdebat dengan teknik yang benar.

Mempraktikkan pembelajaran debat dalam forum diskusi memerlukan media digital secara face to face. Sehingga diperlukannya lah peranan media digital sebagai inovasi pembelajaran pada pembelajaran debat dalam forum diskusi agar bisa dilaksanakan walaupun tidak kondusif seperti pembelajaran tatap muka. Maka dari itu, media pembelajaran digital ini bisa membantu proses pembelajaran pada masa pandemi covid-19 baik guru dan juga peserta didik yang dijadikan sebagai suatu bentuk inovasi dalam pembelajaran. 


\section{Tindakan yang Dilakukan}

\section{a. Kesiapan pendidik dan peserta didik}

Menurut Muhaiminah Jalil (2020) dengan pembelajaran jarak jauh (PJJ) guru dituntut untuk memiliki kesiapan. Korth et al (dalam Muhaiminah Jalal, 2020: 2) seorang guru yang telah siap dalam pembelajaran di kondisi apapun akan mampu meningkatkan kualitas guru. Selain itu, Arini \& Kurniawati (dalam Muhaiminah Jalal, 2020: 2) kesiapan yang dimiliki oleh seorang guru guna menghadapi proses pembelajaran memberi pengaruh besar terhadap keberhasilan pendidikan di sekolah dan guru yang memiliki kesiapan yang baik akan dapat meningkatkan belajar peserta didik. Selanjutnya, pendapat dari Hanifa (2017) guru yang telah memiliki kesiapan untuk melakukan proses pembelajaran dengan mempersiapkan perencana pelaksanaan pembelajaran, implementasi, melakukan evaluasi, dan menindaklanjuti dengan mempertimbangkan beberapa hal yang dianggap penting oleh guru. Maka dalam hal ini bisa disimpulkan bahwa kesiapan dan kematangan guru akan mempengaruhi proses pembelajaran dan keberhasilan apalagi di masa pandemi covid-19.

Bukan hanya pendidik saja tetapi peserta didik juga harus memiliki kesiapan dalam mengahadapi pembelajaran di masa pandemi covid-19. Prawiladilaga (dalam Julia Anis Handayani dkk (2020) mengatakan bahwa aspek penting dalam belajar adalah kesiapan dari peserta didik, karena peserta didik sebagai subjek dalam pembelajaran yang harus diperhatikan dan dibimbing dalam mencapai tujuan pembelajaran.

Dengan demikian, dapat disimpulkan bahwa baik dari segi pendidik maupun peserta didik harus sama-sama memiliki kesiapan yang baik dalam pembelajaran di masa pandemi covid-19. Pendidik yang akan memberikan pengetahuan dan peserta didik yang menerima penjelasan yang diberikan oleh pendidik. Pembelajaran debat dalam forum diskusi perlu kematangan yang mana pembelajaran ini akan mempraktikkan tata cara dala melakukannya.

\section{b. Menguasai aplikasi pembelajaran}


Di masa modern ini banyak sekali media digital yang disediakan untuk memenuhi kebutuhan sehingga menuntut semua khayalak agar khalayak dapat menguasainya sesuai dengan kebutuhan. Sama halnya pada bidang pendidikan, baik pendidik maupun peserta didik mau tidak mau harus bisa menguasai aplikasi pembelajaran dengan tujuan agar keberlangsungan proses pembelajaran tetap berjalan di masa pandemi covid-19. Tidak hanya aplikasi saja tentu penggunaan seperti hp, komputer yang sering di gunakan juga menuntut pendidik maupun peserta didik menguasainya.

Pembelajaran debat dalam forum diskusi memerlukan penguasaan aplikasi berupa face to face yang mana pembelajaran ini tidak bisa dilakukan dengan hanya sebatas suara saja karena debat sangat sering dipergunakan baik untuk olimpiade, menangani suatu permasalahan dan yang lainnya.

\section{Sarana Pendukung}

\section{a. Google meet/Zoom}

Di masa pandemi covid-19 saat ini penggunaan media digital seperti platform virtual yang banyak dipergunakan di berbagai bidang kegiatan salah satunya pendidikan. Menurut Firman dkk (2021) pembelajaran online atau yang dengan istilah lain disebut sebagai pembelajaran daring, secara umum dapat dilaksanakan dengan dua cara yakni secara asinkron dan secara sinkron. Pembelajaran asinkron memungkinkan pendidik untuk memberikan bahan ajar yang dapat diakses oleh peserta didik pada waktu dan tempat yang berbeda. Sementara itu, pada pembelajaran secara sinkron, interaksi yang terjadi bersifat real time sehingga memungkinkan terjadinya komunikasi dua arah antara pendidik dan peserta didik pada waktu yang sama. Dengan hadirnya platform virtual seperti Google meet dan zoom menjadikan pembelajaran debat dalam forum diskusi dapat dilaksanakan secara sinkron.

Hadirnya platform virtual bisa menjadikan inovasi dalam pembelajaran debat dalam forum diskusi. Selain itu, walaupun tempat antra pendidik dan peserta didik berbeda namun pendidik dapat memberikan bahan ajar debat secara dua arah sekaligus antara pendidik maupun peserta didik. Selain itu, 
tata cara pelaksanaan debat forum diskusi juga bisa dilaksanakan secra langsung saat itu juga sehingga pendidik bisa mempraktikkannya kepada peserta didiknya. Menurut hasil penelitian Firman dkk (2021) mengungkapkan bahwa mahasiswa menunjukkan kecenderungan lebih menyukai pembelajaran secara sinkron melalui konferensi video dibandingkan pembelajaran asinkron yang dilaksanakan menggunakan applikasi-applikasi pembelajaran online. Pembelajaran melalui Zoom atau Google Meet dianggap lebih baik karena memungkinkan untuk berkomunikasi secara langsung.

\section{b. Whatsapp/telegram}

Menurut Ikhwan Nur Rois \& Cahya Edi Setyawan (2020) telegram merupakan suatu aplikasi teknologi berbentuk fitur chatting yang dimanfaatkan sebagai salah satu media pembelajaran. Telegram dapat digunakan baik melalui smartphone maupun sistem desktop, selain itu telegram dapat menerima segala format file baik Microsoft word, Microsoft excel, Power point, zip, dan lain sebagainya maupun berupa teks, gambar, video, audio. Pembelajaran debat berbasis forum diskusi sendiri sulit untuk dilakukan dalam penggunaan telegram. Walaupun bisa berupa video namun akan sulit dimengerti oleh peserta didik. Walaupun demikian, telegram sendiri bisa digunakan seperti pengiriman materi oleh pendidik dan nantinya akan dipahami oleh peserta didik.

Whatsapp merupakan salah satu aplikasi chatting yang saat ini bisa dimanfaatkan dalam pembelajaran di tengah pandemi saat ini. Menurut Imam Ja'far Shodid \& Husniyatus Salamah Zainiyati (2020) Whatsapp ialah apliksai berbasis pesan yang memudahkan kita untuk bertukar pesan tanpa dikenai biaya sms, karena Whatshapp memanfaatkan akses internet. Sehingga dengan whatshapp kita dapat mengirimkan file dokumen, file foto, video call, lokasi GPS dan lain-lain. Sehingga, untuk pembelajaran debat sendiri bisa saja dilaksanakan dengan face to face namun hanya bisa diikuti beberapa peserta saja. Tetapi, debat forum diskusi ini bisa saja dilakukan dengan 
aplikasi tersebut dengan penggunaan voice note walaupun wajah antara pendidik dan peserta didik tidak bisa terlihat.

Dari penguraian di atas dapat disimpulkan bahwa Telegram dan WhatsApp bisa digunakan sebagai pembelajaran seperti pengiriman materi, video, penggunaan voice note, dan sarana lainnya.

\section{c. Laptop dah Handphon}

Laptop dan handphone menjadikan sarana pendukung bagi pendidikan. Jika salah satunya tidak ada maka akan sulit pembelajaran daring dilakukan karena segala aspek harus ada laptop atau handphone. Laptop dan handphone tidak hanya pada bidang pendidikan saja tetapi segala bentuk kegiatan. Dengan adanya laptop atau handphone maka memdudahkan dalam berkomunikasi dan aplikasi-aplikasi yang mendukung pembelajaran hanya bisa dikses jika perangkat seperti laptop dan handphone.

\section{d. Memori}

Memori seperti pada handphone merupakan tempat penyimpanan berkasberkas. Di saat pembelajaran daring saat ini sangat dibutuhkan memori yang besar karena banyak materi yang di share pendidik untuk dipahami peserta didik. Pembelajaran debat yang diajarkan kepada peserta didik juga membutuhkan materi sebelum mempraktikkannya. Apa saja teori yang harus dikuasai dan yang lainnya agar pada saat mempraktikkan nanti sudah mengetahui teori dan tata cara pelaksanannya. Selain itu, jika tidak bisanya dilaksanakan dalam google meet dam zoom maka akan dialihkan seperti WhatsApp san telgram yang mana bisa mengirimkan video. Video sendiri juga membutuhkan memori yang cukup.

\section{e. Kuota}

Kuota merupakan sarana penting karena tanpa adanya kuota penggunaan aplikasi pembelajaran tidak bisa dilaksanakan. Pembelajaran daring di masa pandemi saat ini sangat membutuhkan kuota yang memadai agar pembelajaran tetap berjalan. Sama halnya yang disampaikan menurut Lia Nur Atiqoh Bela Dina (2020) berpendapat bahwa kuota internet merupakan 
kebutuhan pokok yang harus disediakan saat melaksanakan pembelajaran daring.

\section{f. Jaringan}

Menurut Novi Rosita Rahmawat dkk (2020) mengatakan bahwa media untuk mengakses dan menyampaikan materi pembelajaran membutuhkan koneksi internet, dan diperlukan paket data. Hal tersebut sangat menunjang adanya pembelajaran daring. Jika jaringan internet tidak stabil maka menyebabkan informasi atau materi yang disampaikan tidak tersampaikan dengan baik. Pembelajaran debat dalam forum diskusi tentu membutuhkan jaringan yang stabil karena mempraktikkannya secara lisan. Jika penyampaian tidak jelas maka akan terganggu dengan proses pembelajaran tersebut.

Dari sarana pendukung media digital dalam pembelajaran debat pada forum diskusi dapat disimpulkan bahwa sarana-sarana pendukung tersebut akan mendukung pembelajaran debat secara daring walaupun tidak maksimal dalam penggunaannya. Penggunaan yang tidak $100 \%$ berjalan dengan lancar tersebut karena ada kendala-kendala yang terjadi tanpa disengaja. Maka hal itu perlu adanya tindak solutif dari kendala-kendala yang terjadi agar bisa mengikuti proses pembelajaran lebih lanjut. Seperti yang disampaikan menurut Zulhafizh \& Silvia Permatasari (2020) apapun keadaannya, aktivitas belajar seseorang tidak harus berkurang secara kualitas maupun kuantitas.

\section{Tindakan Solutif}

a. Jika jaringan tidak bisa dimaksimalkan dengan baik maka tindakan solutif berupa mencari tampar yang memiliki jaringan stabil.

b. Jika kuota habis pada saat pembelajaran atau sebelum pembelajaran dimulai maka tindakan solutif berupa mencari wifi.

c. Jika tidak memiliki laptop dan handphone atau rusak maka tindakan solutifnya berupa meminjam atau bisa pergi ke warnet.

d. Jika memori habis maka tindakan solutifnya berupa memindahkan file ke leptop. 
e. Jika WhatsApp atau telegram tidak bisa digunakan maka tindakan solutifnya berupa pengiriman melalui $e$-mail.

f. Jika google meet atau zoom tidak bisa digunakan maka tindakan solutifnya berupa YouTube.

g. Jika WhatsApp atau telegram tidak bisa digunakan maka tindakan solutifnya berupa google classroom.

Simpulan

Sejak di masa pandemi covid-19 penggunaan media digital semakin meningkat dalam berbagai aspek bidang tak terkecuali bidang pendidikan. Penggunaan media digital pada bidang pendidikan seperti media sosial, aplikasi pembelajaran yaitu google meet, zoom, google classroom, dan yang lainnya merupakan alat untuk keberlangsungan proses pembelajaran secara daring.

Adanya media digital diharapkan mampu untuk melaksanakan proses pembelajaran dengan baik dan pendidik bisa menerapkan inovasi pembelajaran seperti yang sudah banyak diterapkan selama pandemi covid-19. Dengan adanya media digital sebagai inovasi pada pbelaharan debat forum diskusi tidak memberhentikan proses pembelajaran dan semangat pendidik dan peserta didik terus meningkat walaupun dalam situasi pandemi covid-19.

\section{Referensi}

Dina, L. N. A. B. (2020). Respon Orang Tua Terhadap Pembelajaran Daring. THUFULI: Jurnal Ilmiah Pendidikan Islam Anak Usia Dini, 2(1), 45-52. http://riset.unisma.ac.id/index.php/fai/index

Firman., Sari, A. P., \& Firdaus. (2021). Aktivitas Mahasiswa dalam Pembelajaran Daring Berbasis Konferensi Video: Refleksi Pembelajaran Menggunakan Zoom dan Google Meet. Indonesian Journal of Educational Science (IJES), 3(2), 130-137.

Handayani, J. A., Bahij, A. A., Bahar, H., \& Iswan. (2020). Analisis Kesiapan Pembelajaran Daring Peserta Didik Kelas I Sekolah Dasar Negeri Ciputat 04 di Masa Pandemi Covid-19. Seminar Nasional Penelitian LPPM UMJ, 1-5. http://jurnal.umj.ac.id/index.php/semnaslit 
Hanifa, H. (2017). Meningkatkan Kemampuan Guru dalam Menyusun Perencanaan Pembelajaran Melalui Pembinaan Kolaboratif Bagi Guru Kelas V di Dabin II Unit Pendidikan Kecamatan Gedangan. PEDAGOGIA: Jurnal Pendidikan, 6(2), 195. https://doi.org/10.21070/pedagogia.v6i2.939

Jalal, M. (2020) Kesiapan Guru Menghadapi Pembelajaran Jarak Jauh Di Masa Covid-19. Jurnal Pendidikan Islam Anak Usia Dini (SMART KIDS), 2(1), $35-40$.

Rahmawati, N. R., Rosida, F. E., \& Kholidin, F. I. (2020). Analisis Pembelajaran Daring Saat Pandemi Di Madrasah Ibtidaiyah. SITTAH: Journal of Primary Education, 1(2), 139-148.

Rois, I. N., \& Setyawan, C. E. (2020). Penggunaan Aplikasi Telegram sebagai Media Pembelajaran pada Mata Pelajaran Bahasa Arab Peminatan di MAN 1 Kulon Progo. Annual International Symposium on Arabic Language, Culture and Literature (AISALL) 2020, 59-68.

Saputra, P. W., \& Gunawan, I. G. D. (2021). Pemanfaatan Media Pembelajaran Digital Dalam Upaya Meningkatkan Efektivitas Pembelajaran Di Masa Covid-19. Prosiding Webminar Nasional IAHN-TP, 86-95. https://prosiding.iahntp.ac.id

Shodiq, I. J., \& Zainiyati, H. S. (2020). Pemanfaatan Media Pembelajaran Elearning Menggunakan WhatsApp Sebagai Solusi Ditengah Penyebaran Covid-19 Di MI Nurulhuda Jelu. Al-Insyiroh: Jurnal Studi Keislaman, 6(2), 144-159.

Umam, K. (2013). Penerapan Media Digital Dalam Pembelajaran Apresiasi Batik Kelas X SMA Negeri 1 Blega. Jurnal Pendidikan Seni Rupa, 1(1), 100105.

Zufria, I. (2016). Pemanfaatan Media Digital (E-learning) Dalam Memaksimalkan Proses Belajar Mengajar (PBM) Di Perguruan Tinggi. Jurnal Pendidikan Islam dan Teknologi Pendidikan (NIZHAMIYAH), VI(1), 76-103.

Zulhafizh. \& Permatasari, S. (2020). Developing Quality Of Learning In The Pandemic Covid-19 Through Creative And Critical Thinking Attitudes. Jurnal PAJAR (Pendidikan dan Pengajaran), 4(5), 937-949. http://dx.doi.org/10.33578/pjr.v4i5.8010

Zulhafizh, Atmazaki, \& Syahrul R. (2013). Kontribusi Sikap dan Motivasi Belajar Siswa terhadap Hasil Belajar Bahasa Indonesia. Jurnal Bahasa, Sastra dan Pembelajaran, 1(2), 13-28. 


\section{*Data Penulis}

Masni Fatimah, lahir di Pekanbaru, 6 Oktober 2001. Menamatkan jenjang
SMA pada tahun 2020 dan di tahun yang sama melanjutkan studi pada strata
satu Jurusan Pendidikan Bahasa dan Seni di Program Studi Pendidikan Bahasa
dan Sastra Indonesia FKIP Universitas Riau melalui jalur SBMPTN (Seleksi
Bersama Masuk Perguruan Tinggi Negeri). Prestasi yang pernah diraih seperti:
Juara 3 lomba baca puisi di bangku taman kanak-kanak dan karya yang telah ia
hasilkan tetapi masih belum di bukukan yaitu cerpen dan puisi.

Kontak:

Hp/WA : + 6282382637502

Email : masnifatimah28@gmail.com 